\title{
Swift Reliability Test Methodology of 100G High-Speed, Energy-efficient Electro-Absorption Modulated Lasers (EML) for Green Datacenter Networks
}

\author{
Jack Jia-Sheng Huang ${ }^{1,2}$, Yu-Heng Jan ${ }^{2,1}$, Jesse Chang ${ }^{2}$, Yi-Ching Hsu ${ }^{2}$, Dawei Ren ${ }^{2}$, Emin Chou $^{2}$ \\ ${ }^{1}$ Source Photonics, 8521 Fallbrook Avenue, Suite 200, West Hills, CA 91304, USA \\ ${ }^{2}$ Source Photonics, No.46, Park Avenue $2^{\text {nd }}$ Rd., Science-Based Industrial Park, Hsinchu, Taiwan \\ Correspondence: Jack Jia-Sheng Huang, Source Photonics, No.46, Park Avenue $2^{\text {nd }}$ Rd., Science-Based Industrial Park, \\ Hsinchu, Taiwan.
}

Received: June 22, 2016 Accepted: July 5, $2016 \quad$ Online Published: July 11, 2016

doi:10.11114/set.v3i1.1727 URL: http://dx.doi.org/10.11114/set.v3i1.1727

\begin{abstract}
High-speed transceivers are receiving great interest due to the demand for huge data traffic and information storage capacities in the Big Data era. Recently, 100 Gigabit Ethernet (100GbE) has become an IEEE standardized data communication protocol. The $100 \mathrm{G}$ quad small form-factor pluggable (QSFP) transceiver is one of the key technological enablers in the high-speed optical networks. In this paper, we study the reliability current dependence for the four-lambda QSFP $(4 \times 25 \mathrm{G})$ EML devices that are employed in the 100G QSFP transceivers. In order to meet the energy-efficient and environmental requirements, we develop a swift reliability test methodology that can provide fast, accurate reliability assessment to ensure robust long-term field performance. We discuss the acceleration factor and extrapolation for the energy-efficient reliability test.
\end{abstract}

Keywords: Electro-absorption modulated lasers (EML), swift reliability test, reliability test methodology, datacenter network, 100G high-speed, 100 Gigabit Ethernet, energy efficiency

\section{Introduction}

In the Big Data era, ever-increasing data and information storage capacities are required in order to support the consumer applications such as Facebook, Amazon, Google and iPhone (Cukier, 2010; Laney, 2001). The huge data capacity is also critically important for the fundamental research institutions such as the European Organization for Nuclear Research, CERN (Aad et al., 2015; Khachatryan, Bediaga et al., 2015), Stanford Linear Accelerator Center (SLAC) (Neal, 1968; Rees, 1989) and Brookhaven National Laboratory (BNL) (Laurence, 1947; Ting, 1975). For instance, the world's most powerful particle accelerators and detectors at CERN have been built since 1954 to test the predictions and limits of the Standard Model of particle physics. However, the established Model can only describe the $4 \%$ of the known universe while majority of the questions remain unanswered. To further unfold the universe mystery and advance the human civilization knowledge (Huang \& Jan, 2016), CERN Data Center is constructed to store the colossal amount of experimental data, and sends it around the world for analysis.

High-speed optical networks are critical solutions for the datacenter, wireless and cloud computing applications. Various optical transceivers are used in those high-speed transmissions. For example, $10 \mathrm{G}$ and $25 \mathrm{G}$ transceivers are employed in the wireless applications (Basal, 2015). On the other hand, $40 \mathrm{G}$ and $100 \mathrm{G}$ are popular optical platforms for datacenter networks (Basal, 2012). Recently, 100G QSFP transceivers in particular have gained excellent market traction for the datacenter applications (Basal, 2016; Fujisawa, et al., 2011; Cole et al., 2007). The key enablers for the 100G QSFP are the $25 \mathrm{G}$ EML and $25 \mathrm{G}$ photodiode (PD) for the active components of the emitter and receiver. For the latter, the $25 \mathrm{G}$ PD possesses the performance advantages such as high-bandwidth, high responsivity and low-noise (Huang et al., 2016). For the former, the $25 \mathrm{G}$ EML can bring performance advantages including high speed, high extinction ratio and long transmission distance.

On the environmental forefront, the $100 \mathrm{G}$ optical network also needs to comply with the energy efficiency target (Bilal et al., 2013). The green datacenter architecture, for example, is gaining popularity in the future fiber optic network deployment due to its energy compliance. The global leaders in the recent 2015 United Nations Climate Change 
Conference, COP21 have reached the Paris Agreement for all business sectors to pledge for the reduction of climate change (Allison et al., 2015; McNutt, 2015).

Reliability is one of the most important aspects to meet the environmental-friendly, energy-efficient and high-speed datacenters. To ensure robust reliability of the high-speed transceivers, burn-in screen and long-term reliability test on the optical components are crucial (Telcordia, 2004; Fukuda, 1988; Johnson, 2003; Huang et al., 2016; Huang \& Jan, 2016). Traditional qualification procedure requires lengthy reliability test over several thousands of hours (Huang et al., 2005). Such time-consuming reliability test often imposes challenges to meet the targets for energy efficient qualification and short time-to-market (Huang, 2006). In this paper, we present a new swift reliability test methodology that can provide accurate assessment of long-term EML device reliability in timely fashion. We show that quick feedback of reliability qualification to meet environmental energy-efficiency requirement is feasible for 100G QSFP transceivers in the green datacenter network applications.

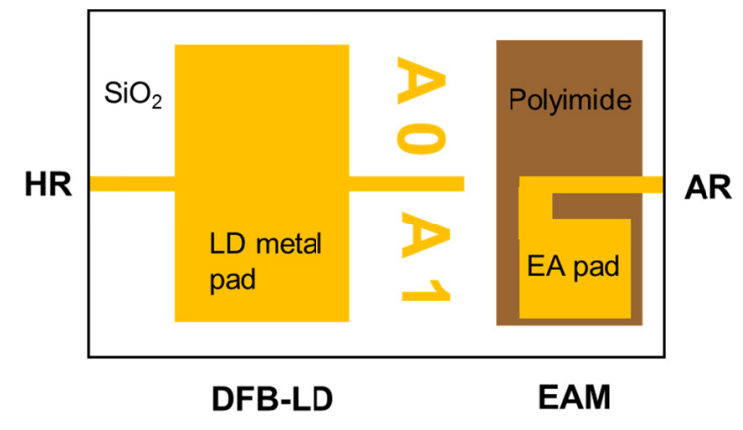

Figure 1. Top-view schematic of the EML device showing the DFB LD and EAM sections

\section{Experimental}

Figures 1 shows the top-view schematic of the fabricated EML structure where the front section consisted of electro-absorption modulator (EAM), and the rear section consisted of distributed feedback laser diode (DFB-LD). The 100G QSFP transceiver was made of 4 channels $(1270,1290,1310 \& 1330 \mathrm{~nm})$ where each channel transmitted a signal rate of $25 \mathrm{G}$.

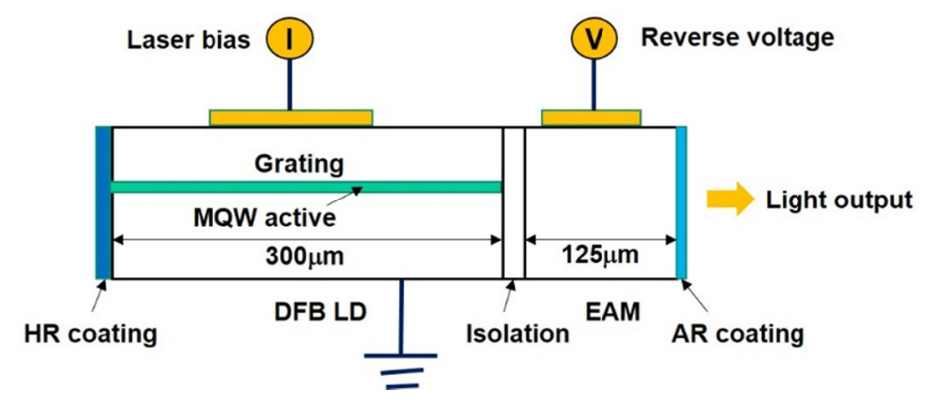

Figure 2. Cross-sectional schematic of the EML device structure

Figures 2 shows the cross-sectional schematic of the EML structure. The EAM incorporated a window region to reduce the reflection in order to achieve the optimal RF performance. The two sections were separated by an isolation region. For both LD and EAM sections, the quaternary InGaAsP multi-quantum well (MQW) and separate confinement (SCH) structures were grown. The $\mathrm{SiO}_{2}$ dielectric layer was deposited for passivation. In the EA section, the low-k polyimide was also deposited to reduce capacitance. The dielectrics were etched in the contact opening process to make ohmic contact with the Ti/Pt/Au p-metal. The wafer was thinned and deposited with n-metal of AuGe/TiAu (Huang et al., 2016; Huang \& Jan, 2016).

To study the reliability, the LD sections were stressed with different levels of currents to establish statistical data. The light versus current (LI) was tested before and after each reliability test interval. Figure 3 shows the LI curve of the EML device before aging. The threshold current $\left(\mathrm{I}_{\mathrm{th}}\right)$ determined by the $\mathrm{LI}$ was around $15 \mathrm{~mA}$ at $45^{\circ} \mathrm{C}$. The laser showed good output power with the EA at OFF state $\left(\mathrm{V}_{\mathrm{EA}}=0 \mathrm{~V}\right)$. The power at the bias of $60 \mathrm{~mA}$ was about $8 \mathrm{~mW}$. 


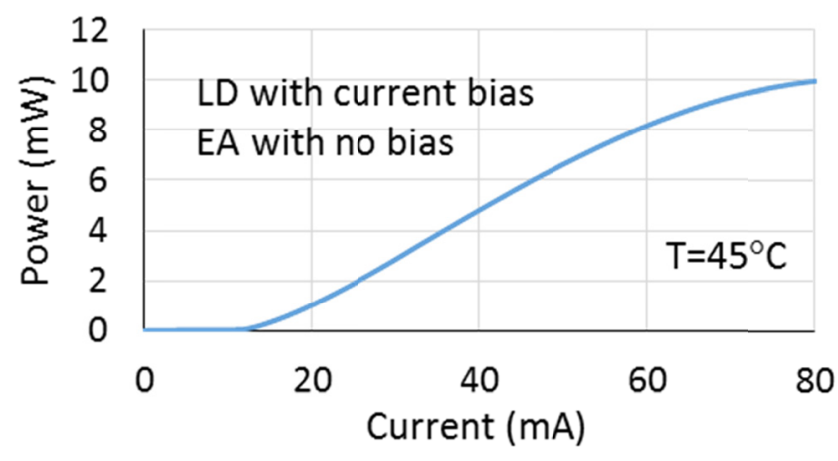

Figure 3. The LI curve of the EML device where the EA section is at OFF state with no voltage bias

\section{Results and Discussion}

\subsection{Traditional Reliability Test}

Figure 4 shows the EML device long-term aging curve of the traditional reliability test where the stress condition was set at the safe regime compared with the operating condition. In this case, the aging condition was $85^{\circ} \mathrm{C}, 85 \mathrm{~mA}$ with reference to the operating condition of $45^{\circ} \mathrm{C}, 60 \mathrm{~mA}$. After $500 \mathrm{hr}$ aging, the $\mathrm{I}_{\mathrm{th}}$ change was $1.3 \%$. Based on the Telcordia requirement, we used $50 \%$ change of $\mathrm{I}_{\mathrm{th}}$ as the failure criterion for end-of-life (Telcordia, 2004). Since all the devices did not reach the failure criterion, the sublinear fitting was applied to the degradation curves to extrapolate the failure times. The failure time was estimated to be about $3.3 \times 10^{6}$ hours. Due to the effect of critical current density $\left(\mathrm{j}_{\mathrm{c}}\right)$, the reliability test time would be very long in order to reach observable $\mathrm{I}_{\mathrm{th}}$ change (Huang \& Jan, 2016).

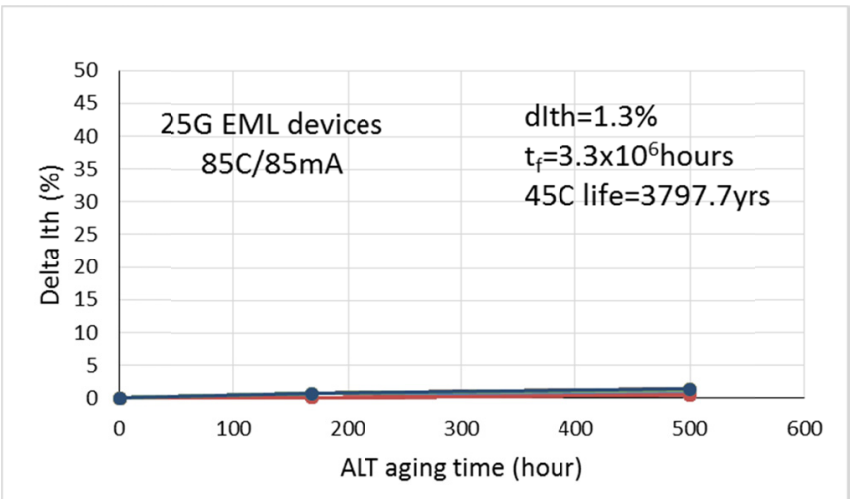

Figure 4. Example of traditional reliability test where the stress was in safe zone, but the $\mathrm{I}_{\mathrm{th}}$ change was very small. The

EML devices were subjected to the aging condition of $85^{\circ} \mathrm{C}, 85 \mathrm{~mA}$

\subsection{Swift Reliability Test: A New Methodology}

For the EML device, we develop the new swift reliability test to accelerate the aging without inducing any irrelevant, new failure mode. Figures 5 and 6 show the $\mathrm{I}_{\text {th }}$ degradation curves of the $25 \mathrm{G}$ EML devices that were subjected to temperature of $100^{\circ} \mathrm{C}$ with the stress currents of 125 and $150 \mathrm{~mA}$, respectively. In both cases, the $\mathrm{I}_{\mathrm{th}}$ changes were more measurable compared with the tester noise. After 500hr, the $\mathrm{I}_{\text {th }}$ changes in Figs. 5 and 6 were 2.9\% and 5.6\%, respectively. The failure times to reach $50 \% \mathrm{I}_{\text {th }}$ change were estimated to be $4.5 \times 10^{4}$ and $1.5 \times 10^{4}$ hours. 


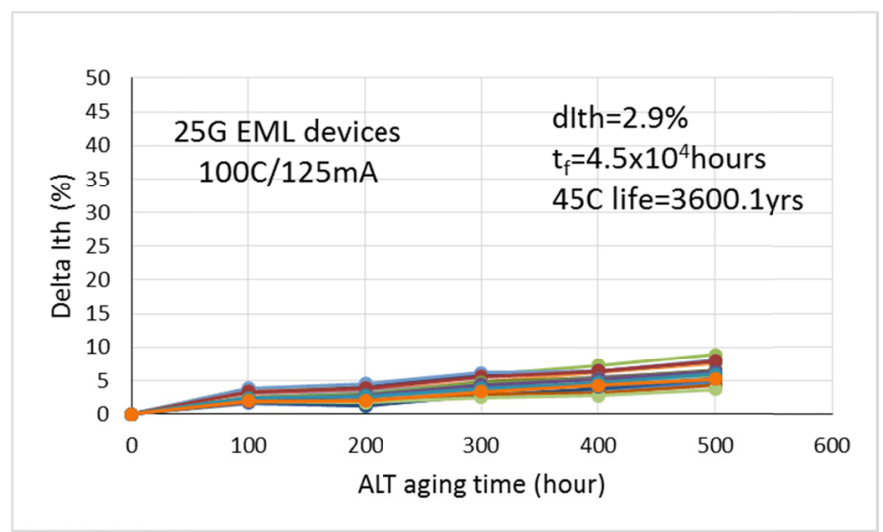

Figure 5. New swift reliability test of EML based on accelerated reliability test condition of $100^{\circ} \mathrm{C}, 125 \mathrm{~mA}$

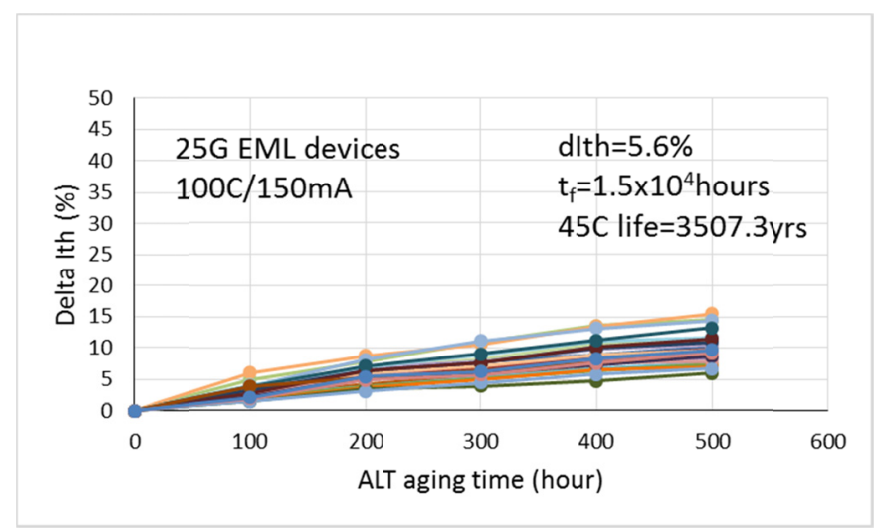

Figure 6. New swift reliability test of EML based on accelerated reliability test condition of $100^{\circ} \mathrm{C}, 150 \mathrm{~mA}$

\subsection{Acceleration Factor and Projected Device Lifetime}

In this section, we examine the acceleration factor of the traditional and swift reliability tests over a wide range of stress current. We recall that the device failure time $\left(\mathrm{t}_{\mathrm{f}}\right)$ follows the modified Black's equation which provides a good empirical description of device degradation where the failure time is a function of stress current and temperature as shown in Equation (1) (Black, 1969; Huang, 2005). The $t_{f}$ is inversely proportional to the stress current (I) described by the current exponent $(\mathrm{N})$. In the exponential term, the Ea is the activation energy, $\mathrm{k}$ is the Boltzmann's constant and $\mathrm{T}$ is the temperature. The constant $\mathrm{A}$ is dependent upon the characteristics of the device. For the temperature dependence, the Ea value of $0.4 \mathrm{eV}$ recommended by Telcordia was used as the conservative estimate.

$$
\begin{gathered}
t_{f}=\frac{A}{I^{N}} \exp \left(\frac{E_{a}}{k T}\right) \\
\operatorname{Ln}\left(t_{f}\right)=\operatorname{Ln}(A)-N \bullet \operatorname{Ln}(I)+\frac{E_{a}}{k T}
\end{gathered}
$$

For the same stress temperature, the current exponent $\mathrm{N}$ can be determined by the slope of $t_{\mathrm{f}}$ versus I plot shown in Fig.7. Taking the natural logarithm, Equation (1) can be rewritten as Equation (2) where the slope of $\operatorname{Ln}\left(\mathrm{t}_{\mathrm{f}}\right) \mathrm{vs.} \operatorname{Ln}(\mathrm{I})$ is equal to $-\mathrm{N}$. It is noted that the slope varies with the stress current. Consequently, the $\mathrm{N}$ value also varies with the stress current. In the traditional test regime, the $\mathrm{N}$ is close to 2 for the stress current in the range of 75 and $125 \mathrm{~mA}$. At the swift reliability test regime, the $\mathrm{N}$ is about 6 for the current range of 125 and $150 \mathrm{~mA}$. At the overstress regime, the $\mathrm{N}$ value increases rapidly to 12 for the range of 150 and $200 \mathrm{~mA}$, likely related to Joule heating. 


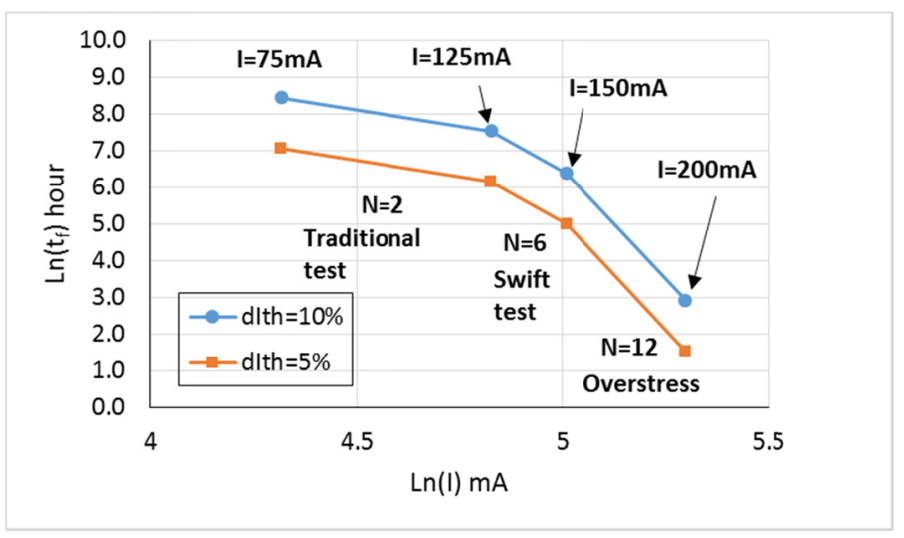

Figure 7. The current exponent of EML based on accelerated reliability test condition of $100^{\circ} \mathrm{C}, 150 \mathrm{~mA}$

Based on the modified Black's equation, we can derive the acceleration factor (AF) as a function of current and temperature as follows.

$$
A F=\left(\frac{I_{2}}{I_{1}}\right)^{N} \exp \left[\frac{E_{a}}{k\left(1 / T_{1}-1 / T_{2}\right)}\right]
$$

The AF for the traditional test $\left(85^{\circ} \mathrm{C} / 85 \mathrm{~mA}\right)$ was 10.2 based on Ea of $0.4 \mathrm{eV}$ and $\mathrm{N}$ of 2 , while the AF for the swift reliability test $\left(100^{\circ} \mathrm{C} / 150 \mathrm{~mA}\right)$ was 2099.6 based on $\mathrm{Ea}$ of $0.4 \mathrm{eV}$ and $\mathrm{N}$ of 6 . The swift reliability test showed improvement in test time efficiency by a factor of 205 . The current acceleration employing $\mathrm{N}=6$ in the swift test regime appeared to be effective in shortening the reliability evaluation process without inducing any harm to the transceiver components. As evidenced in Figs 5 \& 6, the aging curves showed measureable degradation with no thermal runaway.

Figure 8 shows the AF as a function of stress temperature and current. With reference to the device operating condition of $45^{\circ} \mathrm{C} / 60 \mathrm{~mA}$ for EML, the AF increased with increasing temperature for a given stress current. Using the conservative Ea value of $0.4 \mathrm{eV}$, the AF showed weaker temperature dependence compared with the current acceleration. For example, the AF only increased from 8.4 to 20.3 for the stress temperatures of 80 and $105^{\circ} \mathrm{C}$ with the stress current of $85 \mathrm{~mA}$. On the other hand, the AF showed stronger current dependence for a given stress temperature. The AF curves for the stress currents of 75 and $85 \mathrm{~mA}$ corresponded to the traditional reliability test regime; the AFs for 125 and $150 \mathrm{~mA}$ represented the swift test regime; the AF for $200 \mathrm{~mA}$ was for the overstress regime. The AF increased from 8.4 to 1025.4 for the stress currents of 85 and $150 \mathrm{~mA}$ at the stress temperature of $80^{\circ} \mathrm{C}$.

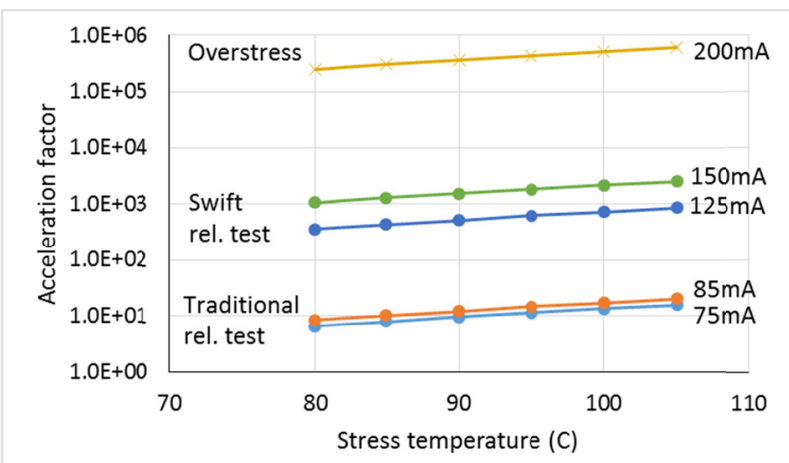

Figure 8. The acceleration factor of EML with reference to the operating condition of $45^{\circ} \mathrm{C}, 60 \mathrm{~mA}$

Table 1. Reliability requirement for semiconductor lasers and comparison between the traditional and swift reliability tests

\begin{tabular}{cccccc}
\hline & $\begin{array}{c}\text { Provisional } \\
\text { qualification }\end{array}$ & $\begin{array}{c}\text { Periodic } \\
\text { reliability } \\
\text { monitoring }\end{array}$ & $\begin{array}{c}\text { Level-2 } \\
\text { qualification }\end{array}$ & $\begin{array}{c}\text { Level-1 } \\
\text { qualification }\end{array}$ & $\begin{array}{c}\text { Extensive test } \\
\text { for defense or } \\
\text { telecom }\end{array}$ \\
\hline $\begin{array}{c}\text { Traditional aging } \\
85^{\circ} \mathrm{C} / 85 \mathrm{~mA}\end{array}$ & $500 \mathrm{hrs}$ & $1000 \mathrm{hrs}$ & $2000 \mathrm{hrs}$ & $5000 \mathrm{hrs}$ & $10000 \mathrm{hrs}$ \\
$\begin{array}{c}\mathrm{S} w i f t \text { reliability test } \\
100^{\circ} \mathrm{C} / 150 \mathrm{~mA}\end{array}$ & $2.4 \mathrm{hrs}$ & $4.9 \mathrm{hrs}$ & $9.8 \mathrm{hrs}$ & $24.4 \mathrm{hrs}$ & $48.8 \mathrm{hrs}$ \\
\hline
\end{tabular}


Table I shows the comparison of test efficiencies between the traditional and swift reliability tests. For the swift test, it is plausible to establish accurate reliability prediction based on significantly reduced test time (by a factor of 205). The extrapolated device lifetimes at the use condition in Figures 4-6 show good quantitative agreement, within 10\% variation. This is important not only for quick time-to-market, but also for environmental-friendly product qualification.

\section{Conclusions}

We have extensively studied the reliability characteristics of the 25G EML devices employed in the 100G QSFP transceivers over a wide range of stress current. We have developed a new swift reliability test methodology that can provide quick qualification feedback with accurate prediction to ensure robust long-term reliability. We have shown that the current dependence was stronger than the temperature dependence for the case of conservative Ea value $(0.4 \mathrm{eV})$. For the traditional aging, the $\mathrm{N}$ value was close to 2. For the swift test, the $\mathrm{N}$ increased to 6 that enabled excellent test efficiency without inducing any new failure mechanism. We have demonstrated that it is feasible to exercise the swift reliability test to shorten the qualification time and to improve the energy efficiency.

\section{References}

Aad, G. et al. (2015). Combined Measurement of the Higgs Boson Mass in pp Collisions at $\mathrm{s}=7$ and $8 \mathrm{TeV}$ with the ATLAS and CMS Experiments. Phys. Rev. Lett., 114, 191803-191806. http://dx.doi.org/10.1103/PhysRevLett.114.191803

Allison, E. H., \& Bassett, H. R. (2015). Climate change in the oceans: human impacts and responses. Science, 350(6262), 778-782. http://dx.doi.org/10.1126/science.aac8721

Basal, J. (2012). Source Photonics expands 40G/100G product family for client side applications. Optical Fiber Communications Conference (OFC, Los Angeles, CA).

Basal, J. (2015). Source Photonics announces availability of extreme temperature-hardened SFP+ transceivers for wireless infrastructure applications. Optical Fiber Communications Conference (OFC, Los Angeles, CA).

Basal, J. (2016). Source Photonics announces shipment of 10,000 single mode 100G QSFP28 modules. Optical Fiber Communications Conference (OFC, Anaheim, CA).

Bilal, K., Khan, S. U., \& Zomaya, A. Y. (2013). Green data center networks: challenges and opportunities. 11th International Conference on Frontiers of Information Technology (FIT). Islamabad, Pakistan, 229-234. http://dx.doi.org/10.1109/fit.2013.49

Black, J. R. (1969). Electromigration failure modes in aluminum metallization for semiconductor devices, Proc. IEEE, 57(9), 1587-1594. http://dx.doi.org/10.1109/PROC.1969.7340

Cole, C., Allouche, D., Flens, F., Huebner, B., \& Nguyen, T. (2007). 100GbE- optical LAN technologies. IEEE Applications \& Practice, 12-19.

Cukier, K. (2010). Data, data everywhere. The Economist (25 February issue).

Fujisawa, T., Kanazawa, S., Takahata, K., Kobayashi, W., Tadokoro, T., Ishii, H., \& Kano, F. (2011). 1.3-m, 4x25Gbit/s, EADFB laser array module with large-output-power and low-driving-voltage for energy-efficient $100 \mathrm{GbE}$ transmitter. Optics Express, 20(1), 614-620. http://dx.doi.org/10.1364/OE.20.000614

Fukuda, M. (1988). Laser and LED reliability update", J. Lightwave Tech., LT-6(10), 1488-1495. http://dx.doi.org/10.1109/50.7906

Generic reliability assurance requirements for optoelectronic devices used in telecommunication equipment, Telcordia Technologies, GR-468-CORE (2004).

Huang, J. S., \& Jan, Y. H. (2016), Interconnected analogy and resemblance: from classical music to modern semiconductor technology. International J. Electrical \& Electronics Eng., 5(2), 1-8.

Huang, J. S., \& Jan, Y. H. (2016). A new kinetics defect diffusion model and the critical current density of semiconductor laser degradation, Appl. Phys. Res., 8(4), 11-19. http://dx.doi.org/10.5539/apr.v8n4p11

Huang, J. S., Jan, Y. H., Chen, H. S., Chang, H. S., Ni, C. J., \& Chou, E. (2016). Predictive reliability model of 10G/25G avalanche photodiode degradation. Appl. Phys. Res., 8(3), 66-74. http://dx.doi.org/10.5539/apr.v8n3p66

Huang, J. S. (2005). Temperature and current dependences of reliability degradation of buried heterostructure semiconductor lasers", IEEE Tran. Device Mater. Reliab., 5(1), 150-154. http://dx.doi.org/10.1109/TDMR.2005.843834

Huang, J. S. (2006). Reliability-extrapolation methodology of semiconductor laser diodes: is a quick life test feasible?, IEEE Tran. Device Mater Reliab., 6(1), 46-51. http://dx.doi.org/10.1109/TDMR.2006.870346 
Huang, J. S., Nguyen, T., Hsin, W., Aeby, I., Ceballo, R., \& Krogen, J. (2005). Reliability of etch-mesa buried-heterostructure semiconductor lasers, IEEE Tran. Device Mater. Reliab., 5(4), 665-674. http://dx.doi.org/10.1109/TDMR.2005.860562

Huang, J. S., Jan, Y. H., Ren, D., Hsu, Y., Sung, P. \& Chou, E. (2016). Defect diffusion model of InGaAs/InP semiconductor laser degradation, Appl. Phys. Res., 8(1), 149-157. http://dx.doi.org/10.5539/apr.v8n1p149

Johnson, L. A. (2003). Reliability counts for laser diodes. Photonics, 37(7), 55-56.

Khachatryan, V., \& Bediaga, I. et al. (2015). Observation of the rare $B_{s}^{0} \rightarrow \mu^{+} \mu^{-}$decay from the combined analysis of CMS and LHCb data, Nature, 522, 68-72. http://dx.doi.org/10.1038/nature14474

Laney, D. (2001). 3D Data Management: Controlling Data Volume, Velocity and Variety. Application Delivery Strategies, META Group (February).

Laurence, W. L. (1947). Atomic Laboratory on Long Island to Be Mighty Research Center. New York Times (March 1, 1947).

McNutt, M. (2015). Climate warning, 50 years later. Science, 350(6262), 721. http://dx.doi.org/10.1126/science.aad7927

Neal, R. B. (1968). The Stanford Two-Mile Accelerator (Chapter 5). New York, NY, USA. W.A. Benjamin, Inc.

Rees, J. R. (1989). The Stanford Linear Collider. Scientific American, 261, 36-43. http://dx.doi.org/10.1038/scientificamerican1089-58

Ting, S. C. C. (1975). Hadron and Photon Production of J Particles and the Origin of J Particles. International Conference on High Energy Particle Physics (Palermo, Sicily, Italy).

\section{$(c)$ EY}

This work is licensed under a Creative Commons Attribution 3.0 License. 